\title{
28 Research Square \\ Short-Term Projection of COVID 19 Cases in Kenya using an Exponential Model
}

Samuel Kiruri Kirichu ( $\nabla$ samkirichu@gmail.com )

Research article

Keywords: COVID-19, Exponential Model

Posted Date: July 10th, 2020

DOI: https://doi.org/10.21203/rs.3.rs-21900/v2

License: (c) (i) This work is licensed under a Creative Commons Attribution 4.0 International License.

Read Full License 


\section{Abstract}

Introduction: The COVID-19 disease has spread to over 200 countries and territories since the first case was recorded in Wuhan, China in December 2019. In Kenya, the first case of COVID-19 was recorded on $13^{\text {th }}$ March 2020 and since then over five thousand cases have been confirmed as of $26^{\text {th }}$ June 2020 . In the same period, one hundred and forty four mortality cases had been recorded in the country. With the rapid changing situation, timely and reliable data is required for monitoring, planning and rapid decision making with an aim of reversing the already deteriorating situation (economic, health, learning among others) in the country.

Methods: The study used the exponential growth model to estimate the daily growth rate and the realtime-effective reproduction number. The study also estimated the naïve and the adjusted Case Fatality Rates.

Results: The naïve-Case Fatality Rate of 26th June 2020 which was the 106 day after the first case was confirmed in Kenya was estimated as 2.5\% while the adjusted Case Fatality Rate with a lag of 2 days was estimated as $2.6 \%$. The daily exponential growth rate was estimated as 0.22 while the real-time reproduction number as of 26th June 2020 was estimated as 1.28 [95\% Cl: $1.27-1.29$ ].

Conclusion: The daily growth rate and the real-time reproduction number indicated that the outbreak was still growing as of the time of analysis.

\section{Background}

The World Health Organization (WHO) defines the Coronavirus Disease 2019 (COVID 19) as an infectious disease caused by a newly discovered coronavirus [1] and is characterized by several symptoms including fever, cough, fatigue, shortness of breath, sore throats and headache [2, 3]. The disease was first reported in Wuhan, China and was declared a Public Health Emergency of International Concern on $30^{\text {th }}$ January 2020. The World Health Organization further recognized the disease as a pandemic on $11^{\text {th }}$ March 2020. As of $26^{\text {th }}$ June 2020 (14:00 Hours GMT), the disease had spread in 216 countries, areas and territories, with 9,473,214 confirmed cases and 484,249 confirmed deaths [4].

In Africa, the first case of COVID 19 was confirmed on $14^{\text {th }}$ February 2020 in Egypt and as of $26^{\text {th }}$ June 2020 (21:30 Hours GMT) all 56 countries and territories in the continent had reported the outbreak of the diseases. In the same period, 348,871 confirmed cases of COVID 19 had been recorded in the continent, with South Africa recording the highest number of 118,317 followed by Egypt with 61,130 cases [5]. Additionally, 9,098 deaths and 166,684 recoveries respectively had been recorded in continent [5]

Kenya recorded the first confirmed case of COVID 19 on $13^{\text {th }}$ March 2020, and as of $26^{\text {th }}$ June 2020 (21:30 Hours GMT) 5,533 cases had been confirmed [6]. In the same duration, the Ministry of Health had confirmed 137 mortality cases and 1,905 recoveries from COVID 19. The confirmed cases of COVID 19 were spread in over forty counties, with Nairobi recording the highest number 
To curb the spread of the disease in the country, the Kenya government instituted a number of measures including closure of school and all social and public gatherings in excess of 10 people. In addition, all international flights to and from the country were suspended as of $25^{\text {th }}$ March 2020 . The government also instituted mandatory quarantine for all returning Kenyans and residents from $22^{\text {nd }}$ March 2020; and from $28^{\text {th }}$ March 2020, a night curfew (7.00 p.m. to 5.00 a.m.) was implemented. Over the days, the government has also intensified contact tracing for all individuals who were exposed to infected cases.

To estimate the COVID 19 caseloads for coming days in Kenya, this paper has estimated the exponential growth rate parameter by modelling the available data. In addition, the paper estimates the effective reproduction number $(R(t))$ which is the number of secondary cases that one primary case would infect in the course of the pandemic. The effective reproduction number is preferred in this paper over the basic reproduction number $(R o)$ in that the former takes into consideration the various measures put in place to curb the spread of the outbreak from time-to-time, unlike the basic reproduction number which assumes no measures to curb the spread of the outbreak are working. Finally, the paper estimates the Case Fatality Rate (CFR) as a measure of mortality. Both estimates are critical for preparedness, surveillance, monitoring, awareness creation and informed decision making in the country.

Though the effective reproduction number and the exponential growth rate were estimated for Kenya, some descriptive analysis including the estimation of the CFR was done for Ghana, Zambia and Ethiopia which also recorded their first cases of COVID-19 in the same week with Kenya. This was done to allow for some comparison in the growth of COVID-19 in Kenya with some selected African countries, which recorded their $1^{\text {st }}$ confirmed case around the same time Kenya did. The first COVID-19 case in Ghana was recorded on $12^{\text {th }}$ March 2020, a day before the Kenya confirmed her first case. In Ethiopia, the first case was confirmed on $13^{\text {th }}$ March 2020, the same day with Kenya while in Zambia, the first case was confirmed on $17^{\text {th }}$ March 2020, 4 days after Kenya confirmed her first case [7].

\section{Methods}

\section{Exponential Growth Model}

The statistical model for an epidemic has five phases as described by Batista M. (2020) [8]. Phase 1 and Phase 2 are characterized by exponential growth. While phase 1 is characterized by a slow growth, phase 2 is characterized by an accelerated fast growth. Phase 3 and 4 are characterized by a negative growth, with phase 4 recording an accelerated negative growth. Phase 5 is the ending phase where limited cases are recorded or are completely not there.

As noted by Chen et. al. [9], the coronavirus epidemic appear to be nonlinear and chaotic, as such, this paper focused on a short-term prediction of COVID-19 cases specifically under phase 1 and 2 of the epidemic in Kenya. 
Assuming a continuous spread of the disease, the number of detected cases are expected to follow an exponential model [10]. The daily cumulative confirmed cases have been estimated using the exponential distribution (equation 1), by fitting the observed confirmed cases in Kenya, (see Equation I in the Supplementary Files)

Reproduction Number $(R(t))$ : The $(R(t))$ was estimated using the Exponential Growth (EG) and the TimeDependent (TD) approach. The TD approach calculates the real-time effective reproduction numbers. As documented by Wallinga and Teunis (2004) [11], the TD estimates the effective reproduction number by averaging the overall transmission and employs the Bayesian Statistical approach. On the other hand, The EG approach estimates the $\mathrm{R}(\mathrm{t})$ by fitting a Poisson regression model on the exponential growth of the outbreak and transforming the exponential growth rate under the assumption of gamma distribution of generalization time. The generalization time (GT) of 5.8 days and standard deviation of 2.6 was used by this paper and was adopted from Linton et. al. (2020) [12]. Finally, the deviance R-squared statistic was used to select the range of possible time period which best fits the Kenyan data for the 106 days.

\section{Case Fatality Rate (CFR)}

This paper also analyzed the COVID-19 Case Fatality Rate (CFR) in Kenya. The CFR also called case fatality ratio in epidemiology is the proportion of people who die from a specified disease among all individuals diagnosed with the disease over a certain period of time [13]. This paper provides the estimates for both naïve CFR (nCFR) and the adjusted CFR (aCFR).

Kucharski and Edmunds (2014) [14] notes that naïve-CFR in the early stage of an outbreak is associated with bias specifically through underestimation since the outcomes for all cases are unknown. Thus, the adjusted CFR (aCFR) which takes into consideration the time between the case confirmation and death (Nishiura et al. (2009) [15]) in the denominator was estimated.

The following formula were used to calculate both CFRs (see Equation II in the Supplementary Files)

For the aCFR, a lag of 2 and 4 days were used due to the absence of data on average number of days to deaths

\section{Source of Data}

The Kenya data used in the analysis was compiled by the author from the daily updates given by the Ministry of Health from $13^{\text {th }}$ March to $26^{\text {th }}$ June 2020; a total of 105 days [6]. Data for Ghana, Zambia and Ethiopia have extracted from ourworldindata.org online webpage [16]. Data Analysis was done using Stata Version 15, MS Excel 2010 and R. In particular, the estimation of $R(t)$ was done using the R0 Package in $\mathrm{R}$

\section{Results}


As of $26^{\text {th }}$ June 2020, a total of 5,533 confirmed cases of COVID-19 had been recorded in Kenya while 137 mortality and 1,905 recovered cases had been recorded in the country. On the same date, 15,834 cases of COVID-19 had been recorded in Ghana, 5,425 in Ethiopia and 1,497 in Zambia. Further, a total of 103 mortality cases had been record in Ghana, 89 in Ethiopia and 18 in Zambia. The growth of confirmed cases in Kenya was slower than in Ghana, but faster than Zambia. Worth to note is that the cumulative cases of COVID-19 in Kenya and Ethiopia had taken a close growth trajectory since the first case was confirmed in either country, which happens to have been on the same day on $13^{\text {th }}$ March 2020 (Figure 1).

On mortality, Kenya recorded her first death from COVID-19 14 days after the first cases was confirmed, while Ghana recorded her first death 9 days after the first case was confirmed. Zambia recorded her first COVID-19 death 16 days after the first case of COVID-19 was confirmed while in Ethiopia, it took 24 days to record the first death from COVID-19. While Ghana recorded her first death more faster than Kenya, Kenya recorded her first death faster than Zambia and Ethiopia. Since the first death was recorded in each of the four countries, the growth of reported deaths in Kenya have been faster than for the other three countries (Figure 2).

Based 7 days rolling average, the daily-confirmed cases in Kenya have been on an upward trend with an accelerated growth recorded from the $60^{\text {th }}$ day after the $1^{\text {st }}$ case was confirmed. The same trend was recorded in Ethiopia. However, Ghana recorded an upward trend till the $50^{\text {th }}$ day when a downward trend was recorded till the $70^{\text {th }}$ day, and an accelerated upward trend was recorded thereafter. On the contrary, Zambia recorded a slow upward trend till the $50^{\text {th }}$ day, when a downward trajectory was recorded till the end of the review period (Figure 3). According to Figure 3, COVID-19 was still on an upward trend in Kenya, Ethiopia and Ghana as of the reference period, while it was on a downward trend in Zambia.

Based on Figures 1 and 3, the trend of cumulative confirmed cases in Kenya and Ethiopia appeared close while the trend of daily new confirmed cases also appeared to follow the same trajectory. As such, a pairwise Pearson's correlation coefficient ( $r$ ) of daily new cases was calculated between both countries. The correlation coefficient was estimated as $0.972(p=0.000)$ indicative of a strong positive association between the daily confirmed cases reported in both countries.

\section{Case Fatality Rate}

As of $26^{\text {th }}$ June 2020, the naïve-CFR for Kenya was estimated as $2.5 \%$, while in Ethiopia it was estimated as $1.6 \%$, in Zambia it was $1.2 \%$ and in Ghana it was $0.7 \%$. Although in the period under review Ghana had recorded the highest number of confirmed cases among the four countries, the country recorded the lowest nCFR in the comparative cohort. Kenya in the same period had recorded the highest nCFR. Despite the close association on the growth of confirmed cases in Kenya and Ethiopia, the nCFR for Ethiopia was lower than for Kenya.

The aCFR with a lag of 2 days was estimated as $2.6 \%$ in Kenya, $1.2 \%$ in Zambia, $1.8 \%$ in Ethiopia and $0.7 \%$ in Ghana. Additionally, the aCFR with a 4 days lag was estimated as $2.9 \%$ in Kenya, $1.3 \%$ in Zambia, 
$1.9 \%$ in Ethiopia and $0.7 \%$ in Ghana. Figures 4, 5, 6 and 7 presents the trends of nCFR and aCFR with a lag of 2 and 4 days in the 4 countries. The aCFR yielded a slightly higher estimate than the nCFR. Both nCFR and aCFR for Kenya was on a downward trend since the $60^{\text {th }}$ day after the first case was confirmed. Similarly, a downward trend of nCFR and aCFR was recorded in Zambia since the $50^{\text {th }}$ day and Ethiopia since the $90^{\text {th }}$ day. However, an increase in nCFR and aCFR was recorded in Ghana since the $87^{\text {th }}$ day.

\section{Reproduction Number in Kenya}

The EG Method is based on the selection of the time upon which the growth is exponential, and the deviance R-Squared statistic was used to select this period. Figure 8 displays the plot of largest deviance R-squared values generated by the data over the 106 days. The period of the epidemic curve which best fitted the exponential growth using the EG Method was of length 9 and corresponded with the dates between $27^{\text {th }}$ April 2020 and $6^{\text {th }}$ May 2020. With this period, the estimate of the daily growth rate was estimated as $r=0.21$ while the corresponding reproduction number $(R(t))$ was estimated as $3.31(95 \% \mathrm{Cl}$ : 2.53 - 4.31) for TD. The reproduction number using different combination yielded different estimates, and Table 1 presents the different estimates for various combination of dates. The $\mathrm{R}(\mathrm{t})$ has been on a downward trend declining to 1.28 [95\% Cl: $1.27-1.29]$ on $26^{\text {th }}$ June 2020

Table 1: Epidemic growth rate and TD Reproduction Numbers based on EG using selected dates

\begin{tabular}{|c|c|c|c|c|}
\hline \multicolumn{2}{|c|}{ Dates } & \multirow{2}{*}{ Growth Rate (/day) } & \multicolumn{2}{c|}{ TD [GT=5.8, SD=2.6] } \\
\cline { 4 - 5 } & & & R(t) & $\mathbf{9 5 \% ~ C I}$ \\
\hline 2 Start Date & End Date & & 17.51 & {$[1.90-93.16]$} \\
\hline $2020-05-04$ & $2020-05-05$ & 0.59 & 4.79 & {$[1.45-13.15]$} \\
\hline $2020-05-04$ & $2020-05-06$ & 0.29 & 3.05 & {$[1.35-6.29]$} \\
\hline $2020-05-03$ & $2020-05-06$ & 0.20 & 3.54 & {$[1.87-6.39]$} \\
\hline $2020-05-01$ & $2020-05-05$ & 0.22 & 3.75 & {$[2.26-6.06]$} \\
\hline $2020-04-30$ & $2020-05-05$ & 0.24 & 3.78 & {$[2.47-5.67]$} \\
\hline $2020-04-29$ & $2020-05-05$ & 0.24 & 3.49 & {$[2.51-4.81]$} \\
\hline $2020-04-29$ & $2020-05-06$ & 0.22 & 3.30 & {$[2.48-4.38]$} \\
\hline $2020-04-28$ & $2020-05-06$ & 0.21 & 3.25 & {$[2.51-4.20]$} \\
\hline $2020-04-27$ & $2020-05-06$ & 0.21 & 1.28 & {$[1.27-1.29]$} \\
\hline $2020-03-13$ & $2020-06-26$ & 0.04 & 1.20 \\
\hline
\end{tabular}

\section{Discussion}

The analysis estimated the exponential growth rate for Kenya as 0.21 indicative of a growing epidemic as of the time of the analysis. The estimate compares with the 0.22 exponential growth rate estimated for Africa by Salihu et.al. (2020) [17]. The effective reproduction number of 3.25 is comparable with other countries like Italy [18], Africa [17] but differs with Northern Africa [19] in their initial stages of the pandemic. With the effective reproduction number of 1.28 [95\% Cl: $1.27-1.29]$ as of $26^{\text {th }}$ June 2020 , it therefore means that the outbreak was growing, and hence not yet under control. 


\section{Conclusion}

The estimated daily growth rate is indicative of a growing outbreak in Kenya meaning that the peak is yet to be reached as of the time of the analysis. Thus, the preventive measures put in place by the government should be continued until the situation is under control.

Given the high positive correlation of the daily new confirmed cases in Kenya and Ethiopia, a detailed indepth modeling of data for both countries is required to document the possible reasons behind the high correlation.

\section{Abbreviations}

aCFR Adjusted Case Fatality Rate

CFR Case Fatality Rate

COVID Corona Virus Disease

EG Exponential Growth

GMT Greenwish Mean Time

GT Generalization Time

$\mathrm{MoH} \quad$ Ministry of Health

MS Microsoft

nCFR Naïve Case Fatality Rate

TD Time Dependent

WHO World Health Organization

\section{Declarations}

Ethics Approval and Consent to Participate

Not Applicable

Consent for publication

Yes 
The Kenya data used in the analysis is freely available in the Ministry of Health Kenya website https://covid19.health.go.ke/

The data used for Ethiopia, Zambia and Ghana is freely available in the cited website [16]

\section{Competing Interests}

None

\section{Funding:}

None

\section{Authors' Contributions}

Kirichu S. K. came up with the idea to predict the daily cumulative cases of COVID 19 in Kenya and wrote the manuscript based on data collated from the Kenya Ministry of Health. The author approves the final manuscript

\section{Acknowledgement:}

Acknowledgement are due to John Gatimu, Lucy Nyambura Njaramba-Mwangi, Moses Ndiritu and Nancy Kiruri who supported in editing and reviewing the article

\section{References}

1. https://www.who.int/health-topics/coronavirus\#tab=tab_1 (3 ${ }^{\text {rd }}$ April 2020)

2. Guan WJ, Ni ZY, Hu Y, Liang WH, Ou CQ, He JX, et al. Clinical characteristics of coronavirus disease 2019 in China. N Engl J Med. 2020. https://doi.org/10. 1056/NEJMoa2002032

3. Chen N, Zhou M, Dong X, Qu J, Gong F, Han Y, et al. Epidemiological and clinical characteristics of 99 cases of 2019 novel coronavirus pneumonia in Wuhan, China: a descriptive study. Lancet. 2020;395(10223):507-13

4. https://covid19.who.int/ (26 ${ }^{\text {th }}$ June $2020,21: 00$ Hours GMT)

5. https://africacdc.org/covid-19/ (26 ${ }^{\text {th }}$ June $2020,21: 30$ Hours GMT)

6. Ministry of Health (Kenya) daily updates by the Cabinet Secretary of Health (latest update on $26^{\text {th }}$ June 2020)

7. https://www.afro.who.int/health-topics/coronavirus-covid-19 (26th June 2020)

8. Batista, M (2020). Estimation of the final size of coronavirus epidemic by the logistic model, ResearchGate, (2020)

9. Chen, X., Yu, B. First two months of the 2019 Coronavirus Disease (COVID-19) epidemic in China: real-time surveillance and evaluation with a second derivative model. glob health res policy 5,7 
(2020). https://doi.org/10.1186/s41256-020-00137-4

10. Nelson KE, Wiliams CM. Infectious disease epidemiology: Theory and practice (3rd edition). Burlington: Jones \& Bartlett Learning; 2014

11. Wallinga J, Teunis P. Different epidemic curves for severe acute respiratory syndrome reveal similar impacts of control measures. Am J Epidemiol. 2004; 160: 509-516

12. Linton NM, Kobayashi T, Yang Y, Hayashi K, Akhmetzhanov AR, Jung S, et al. Incubation period and other epidemiological characteristics of 2019 novel coronavirus infections with right truncation: a

13. Rebeca A. Encyclopedia Britannica. https://www.britannica.com/science/case-fatality-rate (26th June 2020)

14. Kucharski AJ, Edmunds WJ. Case fatality rate for Ebola virus disease in west Africa. Lancet 2014;384(9950):1260.

15. Nishiura H, Klinkenberg D, Roberts M, Heesterbeek JAP. Early epidemiological assessment of the virulence of emerging infectious diseases: a case study of an influenza pandemic. PLoS One 2009;4(8).

16. Max Roser, Hannah Ritchie, Esteban Ortiz-Ospina and Joe Hasell (2020) - "Coronavirus Pandemic (COVID-19)". Published online at OurWorldInData.org. Retrieved from:

'https://ourworldindata.org/coronavirus' [Online Resource] (26 th June 2020, 16:00 Hours GMT)

17. Salihu S. Musa et. al. (2020). Estimation of exponential growth rate and basic reproduction number of the coronavirus disease 2019 (COVID-19) in Africa. Infectious Disease Journal . Research Gate (Pre-print)

18. Jing Yuan, Minghui Li, Gang Lv, Z. Kevin Lu (2020). International Journal of Infectious Diseases, Vol. 95, p311-315

19. Mohamed A. Daw, Abdallah H. El-Bouzedi Travel Med Infect Dis. 2020 May-June; 35: 101671. Published online 2020 Apr 15. doi: 10.1016/j.tmaid.2020.101671 PMCID: PMC7159847

\section{Figures}




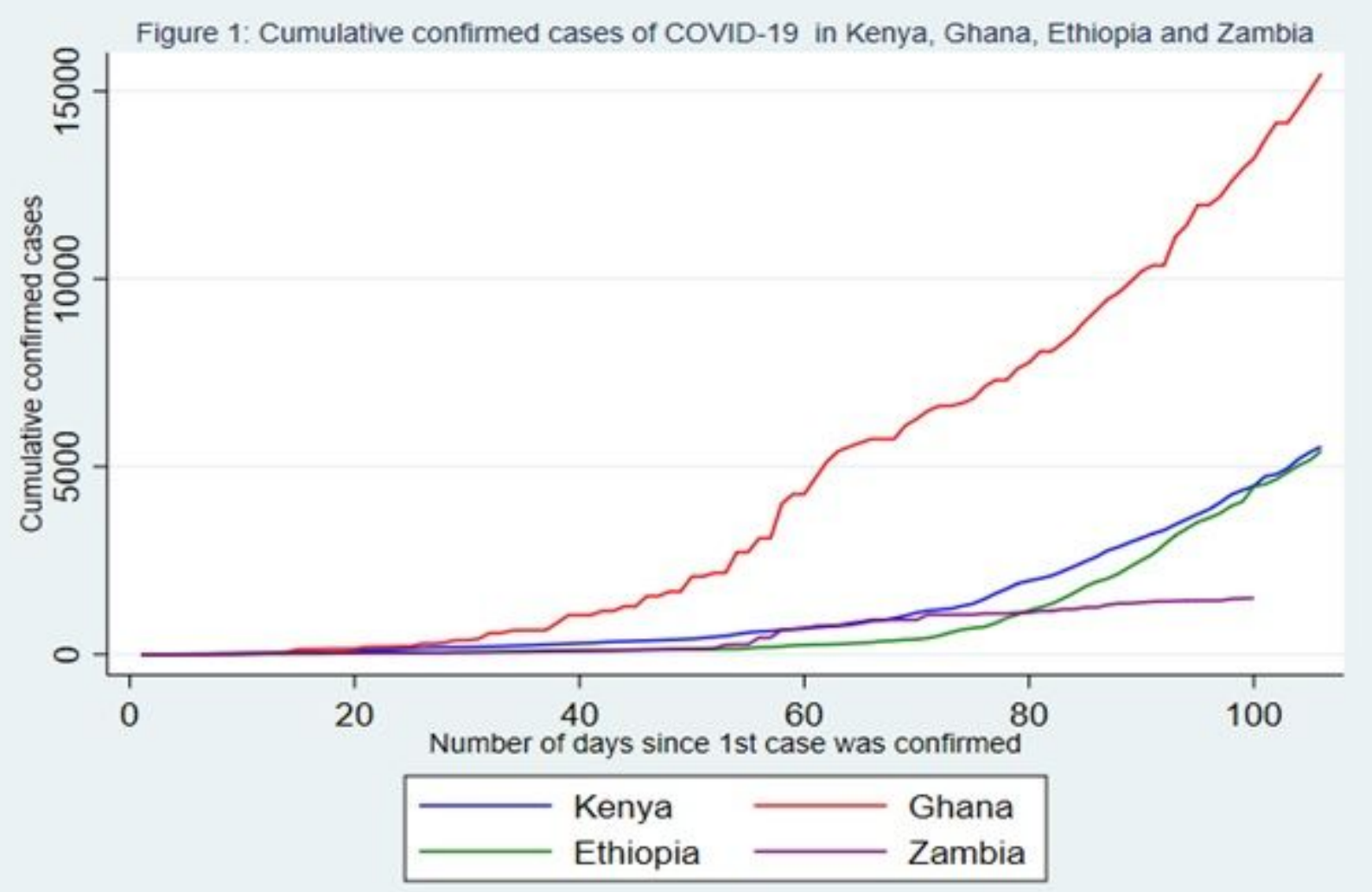

Figure 1

Cumulative confirmed cases of COVID-19 in Kenya, Ghana, Ethiopia and Zambia

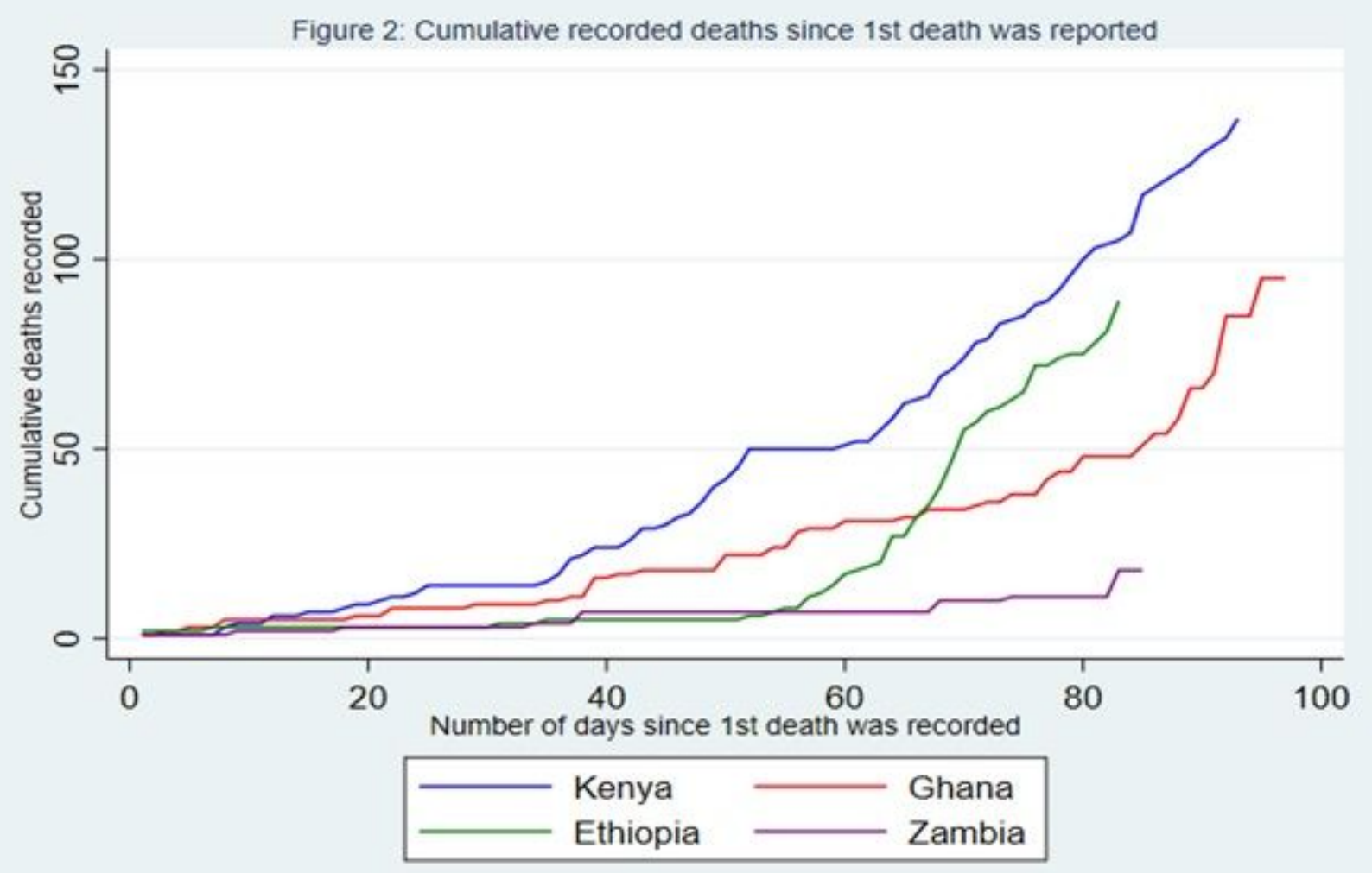

Figure 2 
Cumulative recorded deaths since 1 st death was reported

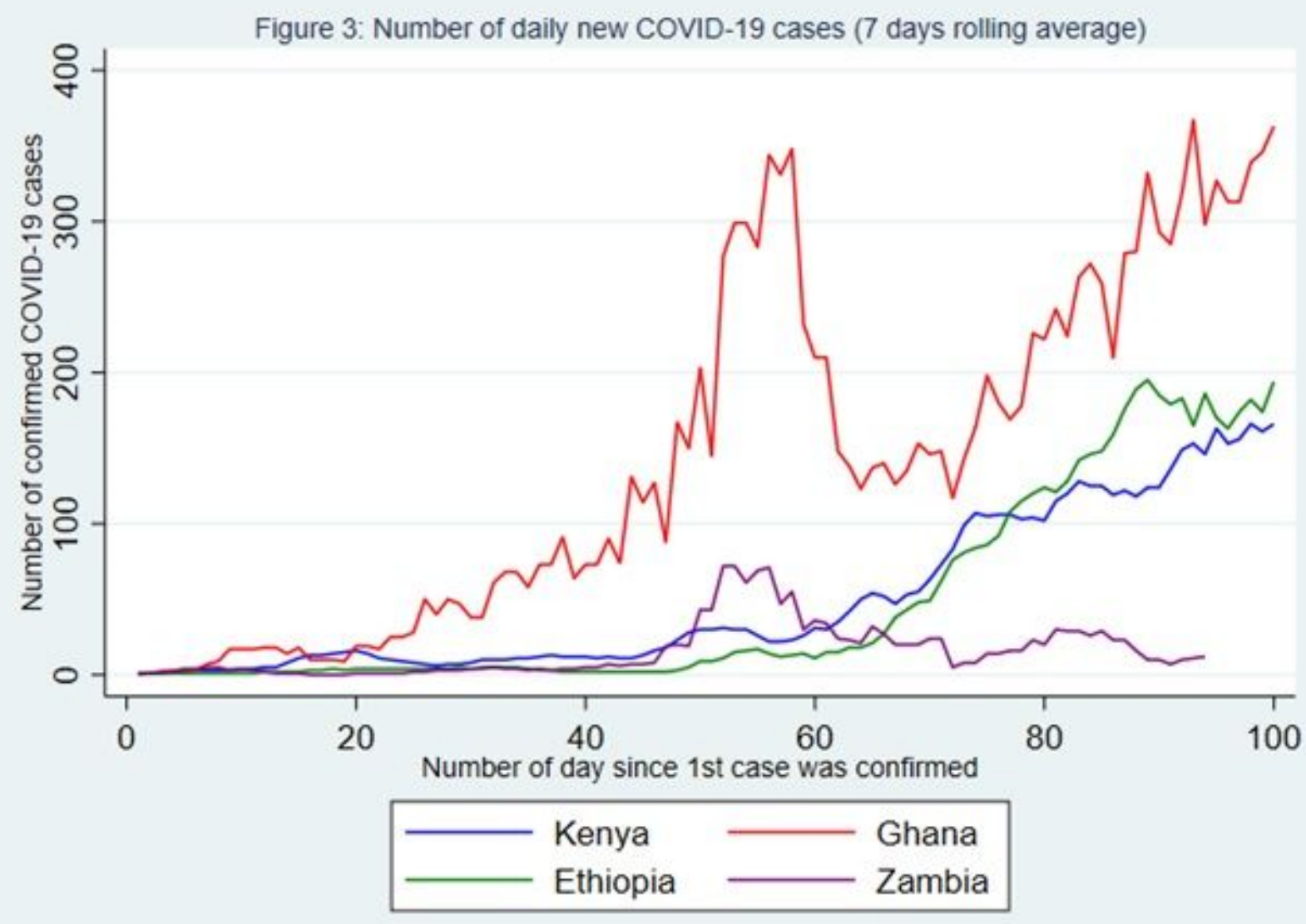

\section{Figure 3}

Number of daily new COVID-19 cases (7 days rolling average)

Figure 4: Case Fatality Rate in Ghana

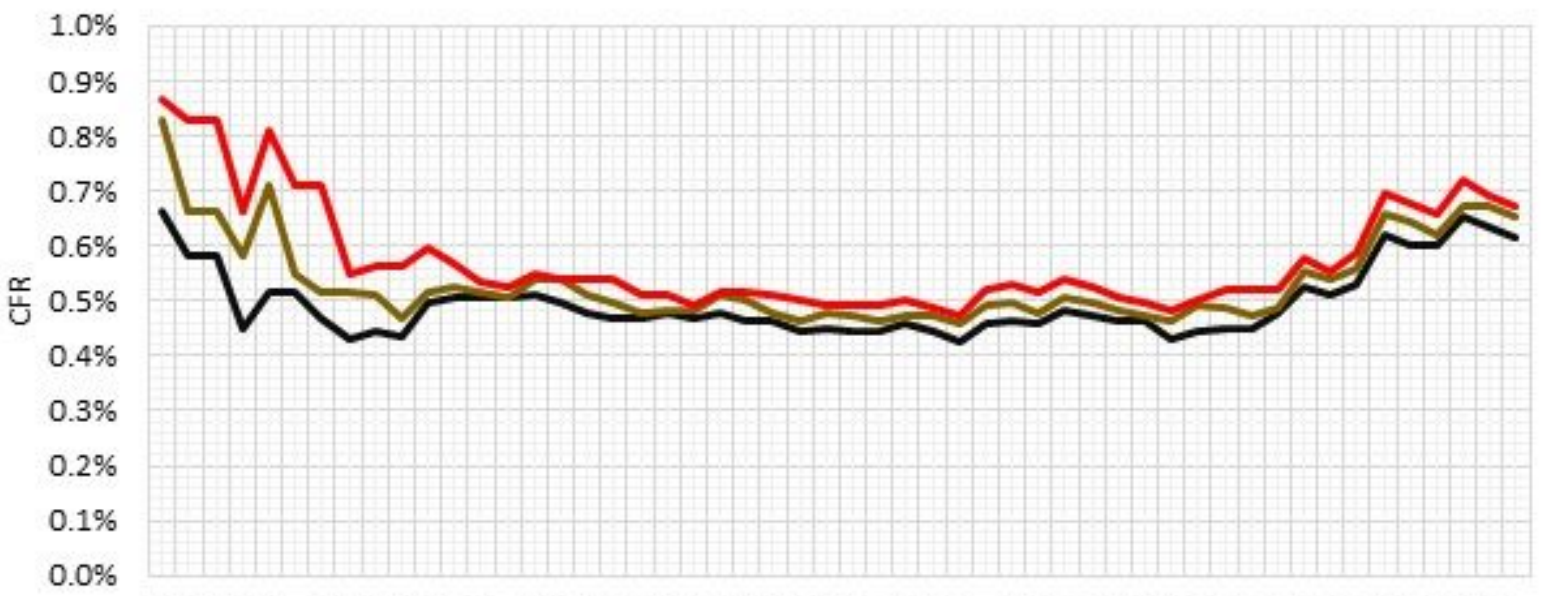

$505254565860 \quad 62 \quad 6466 \quad 68 \quad 7072747678 \quad 80 \quad 828486 \quad 8890 \quad 92949698100$ Day number since 1 st case was confirmed

$-\mathrm{nCFR} \longrightarrow \mathrm{aCFR}(2)-\mathrm{aCFR}(4)$ 
Figure 5: Case Fatality Rate in Ethiopia

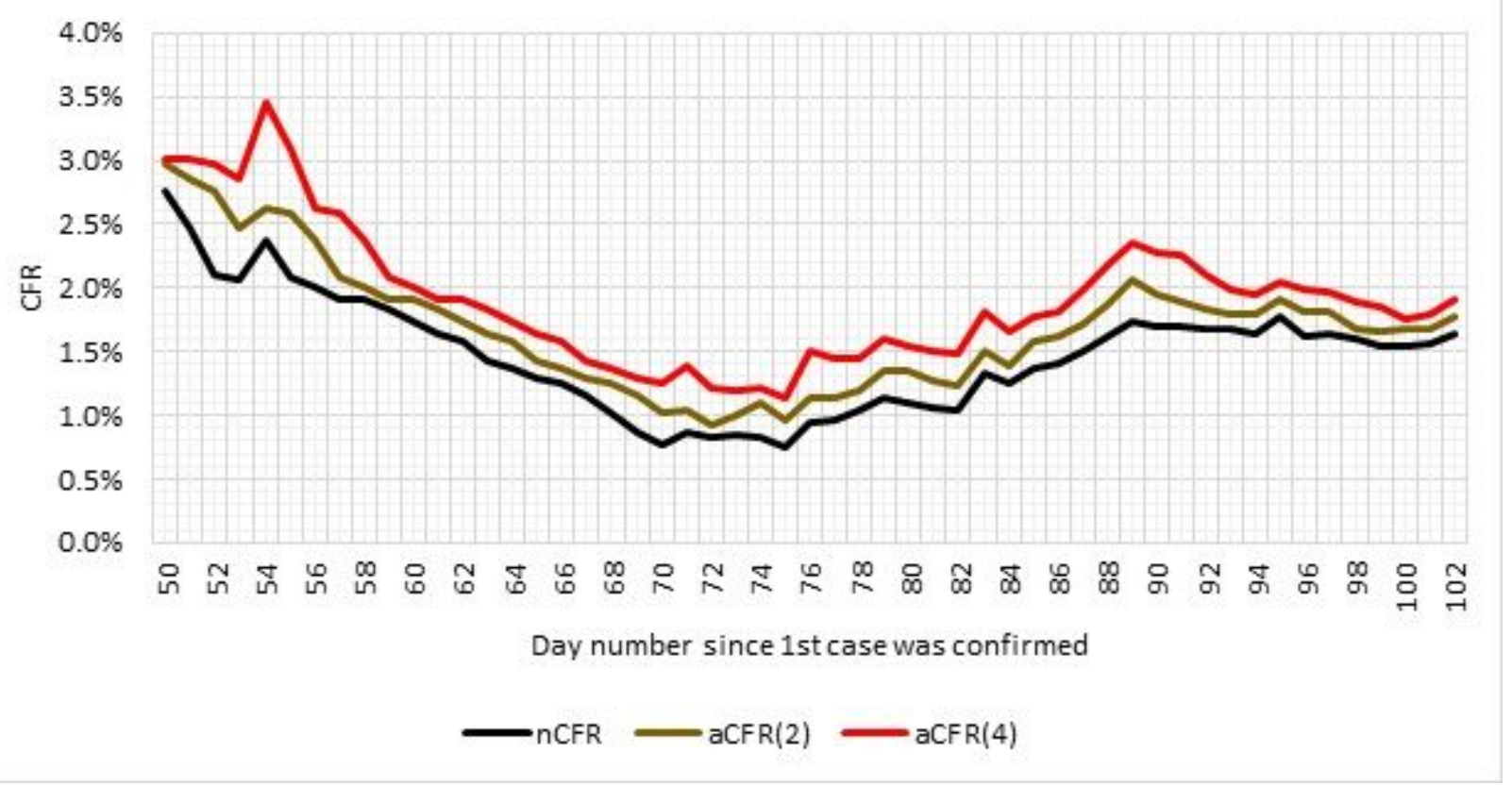

\section{Figure 5}

Case Fatality Rate in Ethiopia

Figure 6: Case Fatality Rate in Zambia

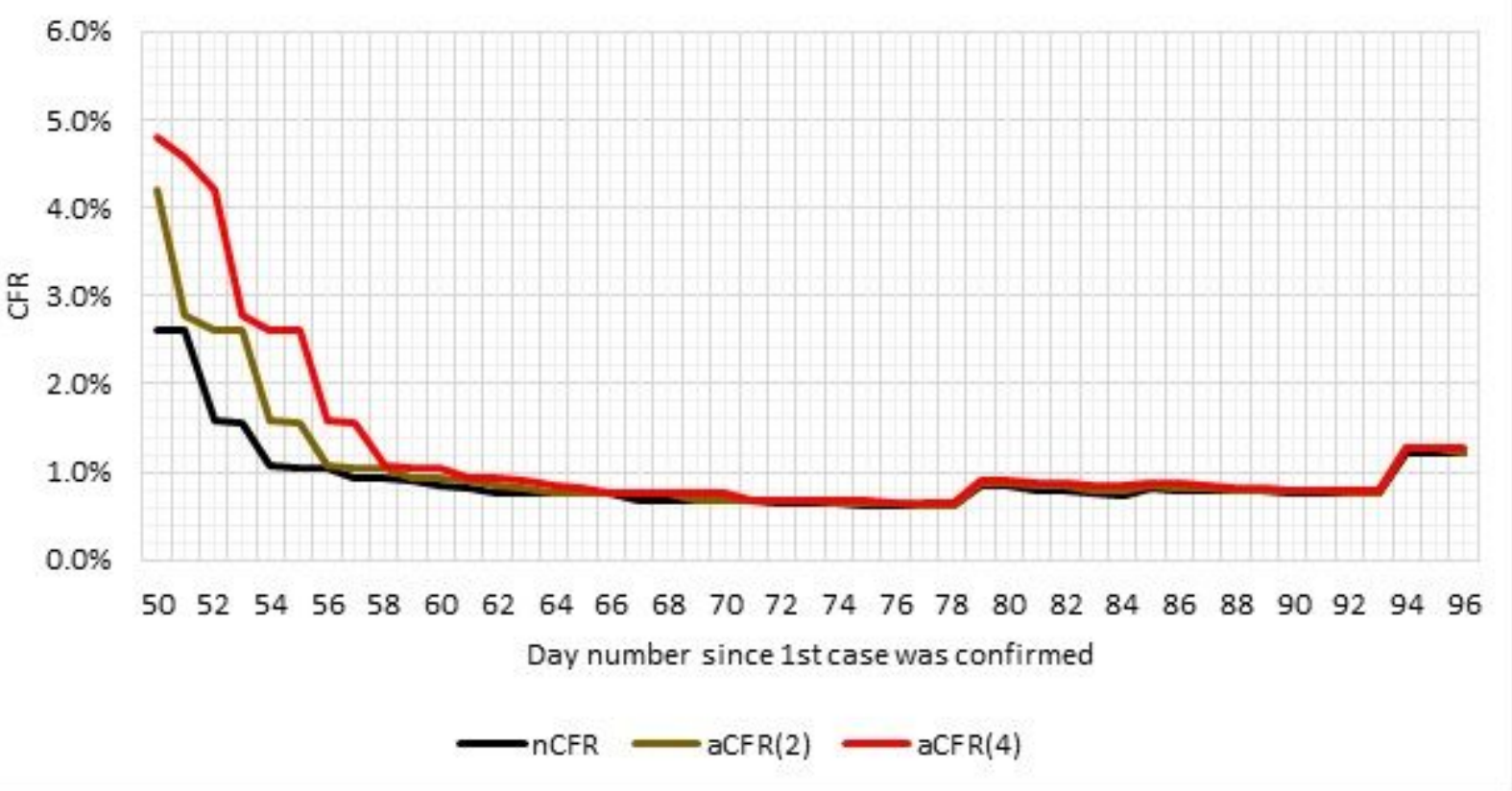

Figure 6

Case Fatality Rate in Zambia 
Figure 7: Case Fatality in Kenya

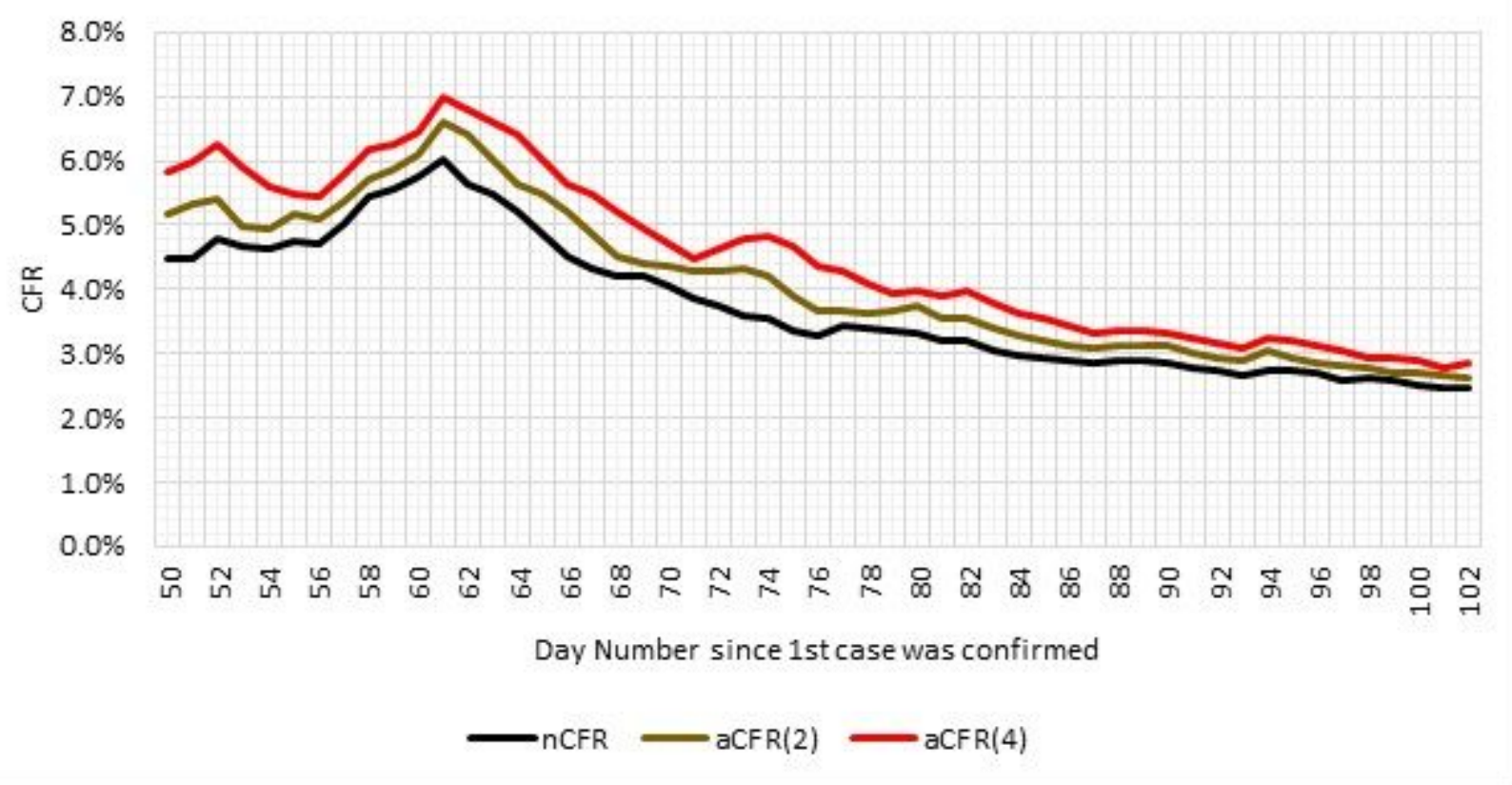

\section{Figure 7}

Case Fatality in Kenya

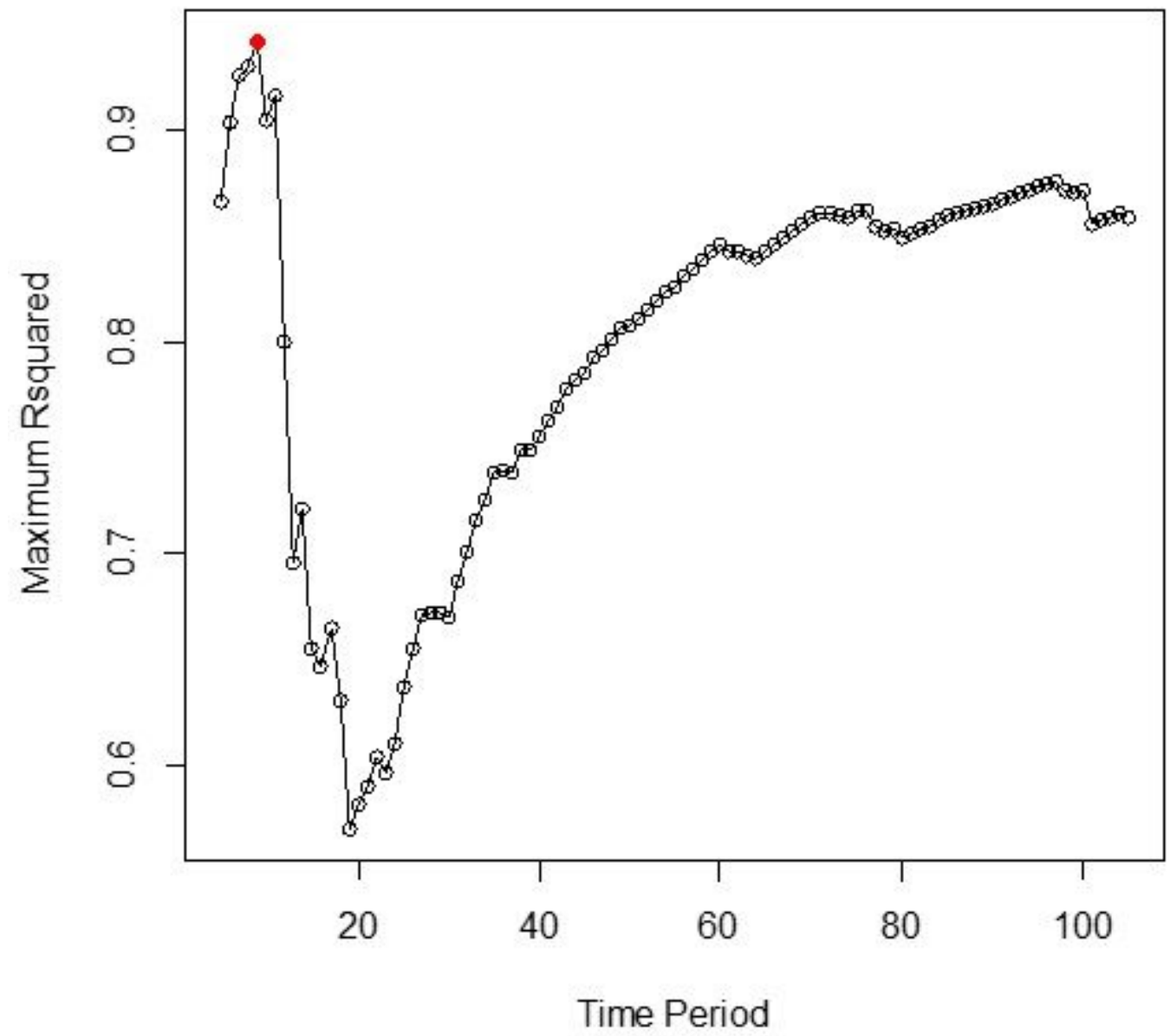

Figure 8 
Goodness of Fit $\left(R^{\wedge} 2\right)$ of the model with time Period

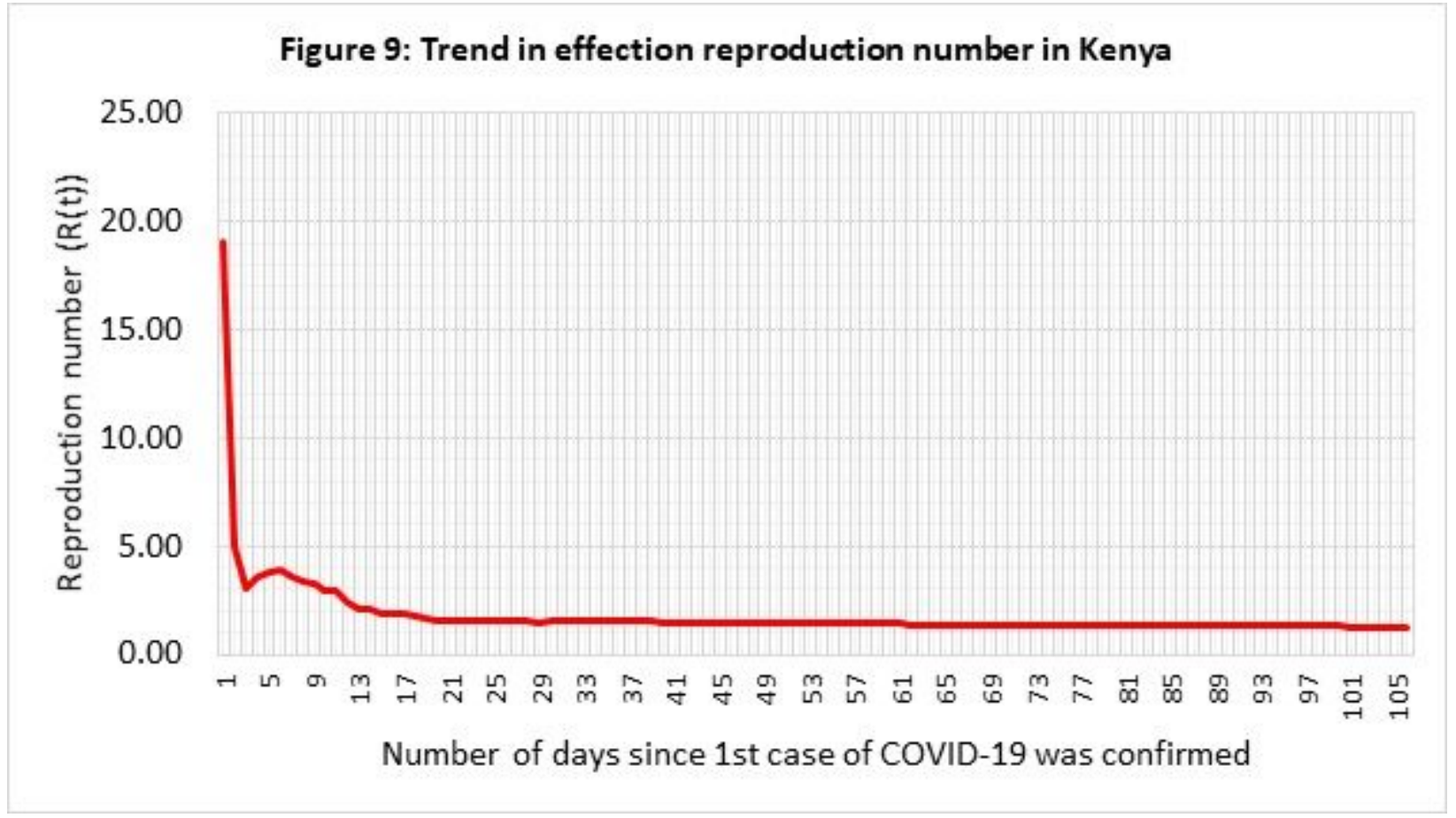

Figure 9

Trend in effection reproduction number in Kenya

\section{Supplementary Files}

This is a list of supplementary files associated with this preprint. Click to download.

- Equations.pdf 